Part of Journal of Research of the National Bureau of Standards, Volume 20, April 1938

\title{
DETECTION OF OXIDATION IN WOOL
}

\author{
By Henry A. Rutherford and Milton Harris ${ }^{1}$
}

\section{ABSTRACT}

A rapid and simple test for detection of oxidation in wool is described. The method utilizes the oxidizing value of some of the intermediate oxidation derivatives of the disulfide groups in wool, and is based on the ability of oxidized wool to convert a ferrous salt into ferric salt. The latter in the presence of thiocyanate gives the characteristic red color of ferric thiocyanate.

\section{CONTENTS}

I. Introduction

II. Description of test

III. Results

IV. References

\section{INTRODUCTION}

The susceptibility of wool to deterioration during wet treatments, especially with alkaline reagents, is appreciably increased if the wool has previously been oxidized [1]. ${ }^{2}$ Damage resulting from oxidation may be produced during bleaching processes, during processes such as chlorination and bromination for producing unshrinkable finishes, and in aging conditions involving exposure to strong light, air, and moisture. Often such damage is not detectable by ordinary physical testing methods. It may, however, be accentuated during the subsequent processing of the fiber. In addition, it has been shown to affect the dyeing properties of the fiber [2] and the durability of woolen materials [3]. The detection of oxidation in wool is therefore of considerable importance.

Two tests for oxidized wool, the alkali-solubility [3] and the lead acetate tests [4], have been suggested by Smith and Harris. The former test, although somewhat time-consuming, has the advantage of giving values which have some quantitative significance, and it can be used as a control method in practical wool processes. The latter test is a qualitative one and more rapid, but it fails if the wool has been exposed to light of great intensity.

\footnotetext{
1 Research Associates at the National Bureau of Standards, representing the American Association of Textile Chemists and Colorists. This work was aided by a grant from the Textile Foundation, Inc.

\& Numbers in brackets indicate literature references at the end of the paper.
} 
More recent investigations have indicated that the oxidizing value of some of the intermediate oxidation products of the disulfide groups in wool can be utilized as a test for the detection of oxidation. One method based on this fact depends on the ability of oxidized wool to liberate iodine from hydrochloric acid-potassium iodide solutions [5]. The iodine is determined by direct titration with sodium thiosulfate, but the values have no quantitative significance with respect to the extent of oxidation since only sulfur that is oxidized below the sulfonic acid state is reduced. The method was found to be impractical as a mill laboratory test since the reducing solution is unstable, the reductions must be done in the dark at a constant temperature, and the titrations are difficult because some of the liberated iodine is absorbed by the wool.

A more satisfactory test, which is described in this report, utilizes the ability of oxidized wool to convert a ferrous salt to a ferric salt, which in the presence of a thiocyanate gives the characteristic red color of ferric thiocyanate. Although the test is a qualitative one, it has the advantages of being rapid and simple, and of giving a positive test for wool which has been oxidized by photochem cal reactions.

\section{DESCRIPTION OF TEST}

The fo lowing three solutions are required for the test.

1. Solution $A$ consists of equal parts by volume of acetone (reagentgrade) and distilled water, acidified by the addition of 1 percent by volume of a $6 N$ solution of sulfuric acid. The acetone inhibits dissociation of the ferric thiocyanate and helps to preserve the color $[6,7]$.

2. Solution $B$ is prepared by dissolving about $1 \mathrm{~g}$ of potassium thiocyanate in $30 \mathrm{ml}$ of solution $A$.

3. Solution $C$ is prepared by dissolving about $1 \mathrm{~g}$ of ferrous ammonium sulfate (reagent-grade) in a solution containing $50 \mathrm{ml}$ of solution $A$ and $15 \mathrm{ml}$ of $6 \mathrm{~N}$ solution of sulfuric acid. Solution $C$ must be prepared immediately before the test is made, since some of the ferrous salt is oxidized by air. The best results are obtained if the solution is prepared in an atmosphere of carbon dioxide or nitrogen.

About $1 \mathrm{~g}$ of wool is cut in small pieces and placed in a $125-\mathrm{ml}$ Erlenmeyer flask containing $40 \mathrm{ml}$ of solution $A$ and $5 \mathrm{ml}$ of solution $B$. The solution is boiled for several minutes to insure displacement of the air in the flask by water and acetone vapors. As soon as the heating is discontinued, $5 \mathrm{ml}$ of solution $C$ is added and the flask immediately stoppered. For controls, similar tests are made at the same time on a sample of wool known to be unoxidized and on the reagents in the absence of wool. A recommended procedure is to heat all of the test solutions on a hot plate at the same time.

A pink color may develop in the control solution containing only the reagents, and thus decrease the sensitivity of the test. This is overcome by the addition of a measured amount of distilled water until the color just disappears. An equal volume of water is then added to the other test solutions. Under these conditions, unoxidized wool produces no color, while oxidized wool will give various shades of pink depending upon the degree of oxidation of the sample.

The development of a pink color in the test solution prior to the addition of solution $C$ indicates the presence of iron in the wool. In 
such a case, the wool must first be washed with a sufficient number of changes of a very dilute solution of sulfuric acid in distilled water to remove all of the iron.

\section{RESULTS}

The method as described gave positive tests for wool bleached with hydrogen peroxide, for chlorinated and brominated wool, and for wool which had been exposed in the presence of air and moisture to the radiation of a glass-enclosed carbon-arc lamp. Negative tests were obtained for samples of wool irradiated in atmospheres of moist or dry nitrogen and in very dry air. Samples of wool which had been bleached with hydrogen peroxide and subsequently treated with sulfurous acid also gave negative results.

Like the reduction method, using the hydrochloric acid-potassium iodide solutions, the method should have no quantitative significance. Further evidence of this was obtained when it was found that a sample of wool which had been bleached for 2 hours with a solution containing 0.6 percent of hydrogen peroxide produced a deeper pink color in the test than was produced by a sample of wool bleached with a 1.7per cent solution for the same length of time. In other words, the latter solution oxidized a greater number of disulfide groups to states of oxidation which resisted reduction. That the method has practical application as a qualitative test, however, is indicated by the fact that a positive test was obtained even with wool which was oxidized with a 3-percent solution of hydrogen peroxide for 24 hours. Such a treatment is far more drastic than any encountered in wool processing, yet not all of the disulfide groups were oxidized to a stage at which they resisted reduction.

\section{REFERENCES}

[1] J. Research NBS 16, 301 (1936) RP875; Am. Dyestuff Reptr. 25, P180 (1936).

[2] J. Research NBS 19, 81 (1937) RP1012; Am. Dyestuff Reptr. 26, P416 (1937).

[3] J. Research NBS 17, 577 (1936) RP928; Am. Dyestuff Reptr. 25, P542 (1936).

[4] J. Research NBS 16, 309 (1936) RP876; Am. Dyestuff Reptr. 25, P183 (1936).

[5] J. Research NBS 18, 623 (1937) RP 998; Am. Dyestuff Reptr. 26, P413 (1937).

[6] Ind. Eng. Chem., Anal. Ed. 9, 453 (1937).

[7] J. Biol. Chem. 1, 451 (1906).

Washington, January 15, 1938. 